\title{
Correspondence
}

\section{Training in adult general psychiatry}

Sir: Deahl \& Turner's cri de coeur (Psychiatric Bulletin, June 1998, 22, 339-340) will have struck chords of recognition in many beleaguered and demoralised general psychiatrists. However, one word was missing from both their editorial and the accompanying article (Milton, 1998) - psychotherapy. This was odd since the authors discuss transference, the disappointment felt by newly appointed consultants about lack of direct patient contact and dual training for specialist registrars (SpRs) - including presumably dual training in general psychiatry and psychotherapy - which they merely describe as an "escape route".

Consultant posts which combine a defined general psychiatry component with a specific but limited psychotherapy responsibility are currently rare but potentially attractive. The psychotherapy component might involve responsibility for psychological interventions in psychosis, an eating disorder service, a service for patients with borderline personality disorder or a psychotherapy day hospital. Leavening general psychiatry in this way can go some way towards addressing the discontent which Deahl \& Turner so accurately depict. A required psychotherapy attachment as part of an SpR programme would be a first step towards this, and dual trained SpRs would be particularly well equipped to do such work. Can the College endorse such training, and can commissioners and trusts be persuaded to fund the consultant posts needed?

MiLTON. J. (1998) So who wants to be a consultant general psychiatrist. Psychiatric Bulletin, 22, 345-347.

JEREMY HOLMES, Consultant Psychiatrist/Psychotherapist, Department of Psychiatry, North Devon District Hospital, Raleigh Park, Barnstaple, Devon EX31 $4 J B$

\section{Literature and clinical decision-making}

Sir: James Warner \& Robert Blizard (Psychiatric Bulletin, June 1998, 22, 342-344) provide an llluminating account of the torment to be experienced by the tiro seeking to turn booklet learning into clinical practice. At the same time they add to the literature from academic nonclinicians who seem to be determined to deny older people with dementia access to donepezil, and presumably other anticholinesterase inhibitors.

Perhaps I could put Drs Warner \& Blizard out of their misery and at the same time reassure their patient's wife and perhaps even their patient, that common sense or clinical sense still has a part to play in medical practice.

There is an accumulation of evidence that the anticholinesterase inhibitors improve cognitive function, reduce non-cognitive symptoms and improve activities of every day living, in a proportion of patients suffering from Alzheimer's disease. Not everyone obtains improvement and there may be flaws which the purist will find in both the design and presentation of studies. Nevertheless most people will understand that these compounds hold out the prospect that some patients will gain benefit from a medication where, hitherto, there has been no hope that any medicine would achieve benefit. What the patient's wife is asking is that her husband be given the opportunity to see whether donepezil will help him. If the compound is tried and there is no change for the better she will be the first to agree with the clinician that there is no point in pressing on with the treatment. If, however, there is improvement or the arrest of a pattern of decline, both she and the clinician will be pleased, for this is not what their experience has led them to expect from the natural history of the disorder.

The clinical method is that, having reviewed the literature, weighing the possibility of benefit and the risk of adverse effects and explaining these to the patient and carer, the consultant who is familiar and confident in managing patients with this condition will prescribe the new treatment and monitor the outcomes.

Torment and headaches gone. Next patient please.

D. Jolley, Professor in Old Age Psychiatry/ Medical Director, Wolverhampton Health Care NHS Trust, Penn Hospital, Penn Road. Wolverhampton, West Midlands WV4 5HN

\section{Licence to export methylphenidate}

Colleagues who work with substance misusers are no doubt familiar with the regulations about carrying prescribed controlled drugs when travelling abroad. 